Chapter 8

\title{
Atherosclerosis-Susceptible and Atherosclerosis-Resistant Pigeon Aortic Smooth Muscle Cells Express Different Genes and Proteins in vitro
}

\author{
J. L. Anderson, S. C. Smith and R. L. Taylor Jr. \\ Additional information is available at the end of the chapter \\ http://dx.doi.org/10.5772/52948
}

\section{Introduction}

This review describes theories of human atherogenesis and experimental results evaluating gene or protein expression in the pigeon model for spontaneous atherosclerosis. The spontaneous disease in the pigeon differentiates from other animal models that require manipulation (genetic, nutritional, environmental) to induce the disease state. Both susceptible and resistant pigeons have been studied with susceptibility being inherited as an autosomal recessive trait. The aims are to present the pigeon data in comparison to current theories of the human disease.

Atherosclerotic cardiovascular disease is the leading cause of death in economically developed countries. The underlying cause(s) remains unclear despite a variety of hypotheses that have attempted to explain the initiation of atherosclerotic lesions. Many genetic factors that contribute to lesion progression and the probability of plaque rupture have been identified in the general population. All forms of heart disease have a strong familial component. However, little is known about the specific genes that determine disease predisposition or how such genes interact with each other and the environment to initiate foam cell formation in any one individual. Numerous, complex gene-environment interactions are believed to be involved in the disease [1] and "although there has been considerable success in identifying genes for the rare disorders associated with atherosclerosis, the understanding of genes involved in the more common forms is largely incomplete" [2]. New molecular markers need to be developed in order to identify susceptible individuals prior to the appearance of clinical symptoms. Until the heritable component of atherosclerosis susceptibility is understood, correlation of various risk factors with specific metabolic or pathological features will be difficult to assess, and prevention efforts will remain equivocal. 


\section{Theories of human atherogenesis}

Many theories have been proposed to explain atherosclerotic lesion initiation in the aorta although there are model-specific differences in the order of events. The pathological steps common to all theories of atherogenesis are:

a. Site specific proliferation of intimal smooth muscle cells

b. Elaboration of excessive and/or abnormal extracellular components

c. Accumulation of lipids within and around cells

d. Entry of monocytes/macrophages into area of proliferation

The abnormal accumulation of lipid within smooth muscle and macrophage cells could arise from increased infiltration (influx), increased retention, decreased efflux, and/or increased lipid biosynthesis by the cells themselves [3-9].

\subsection{Lipid infiltration theory}

The lipid infiltration theory states that arterial wall cells will accumulate lipid if there is a high circulating blood lipid concentration, or a consistently elevated low-density lipoproteins (LDL). In the healthy human aorta, circulating LDL particles are incorporated into vascular smooth muscle cells (VSMC) by receptor-mediated endocytosis. In atherosclerosis, the rate of LDL influx could overwhelm these receptors, causing the excess lipid to be taken up by scavenger receptors. Modified lipoproteins such as oxidized [10], acetylated [11], or particularly small $(<70 \mathrm{~nm})$ [12], LDL are thought to slip through the loose junctions between endothelial cells and accumulate in the intima intact. In these cases, because of their altered conformation, it is hypothesized that the modified LDL molecules are readily incorporated into VSMC by uncharacterized scavenger receptors. As foam cells develop and burst, macrophage cells are recruited to the region. The precise mechanism of how cholesterol from circulating LDL enters the intima to be incorporated in the developing foam cell is not clear. In addition, the lipid infiltration theory does not, on its own, account for the SMC proliferation observed prior to lipid accretion.

If lipid infiltration of any type is coupled with decreased HDL levels, there will be reduced cholesterol clearance (efflux) from the cells, and the sterol will remain trapped. In addition, the innermost arterial cells are in a state of chronic hypoxia ]13]. If the fatty acids released by neutral cholesterol ester hydrolase (NCEH) are not completely oxidized, the metabolites will accumulate at an accelerated rate [14], and can potentially serve as substrate for endogenous cholesterol and/or triacylglycerol (TAG) synthesis. There is compelling evidence indicating that the increase of intracellular cholesterol is at least partly the result of biosynthesis, and not circulating lipoprotein [15] uptake. However, this mechanism is not explained by any of the current theories of atherogenesis, which are mainly focused on the infiltration and retention of plasma lipids and their subsequent inflammatory effects. 


\subsection{Response to retention theory}

The response to retention theory [16] is a proposed explanation for increased circulating blood lipid retention. According to this theory, as proteoglycans (PG), especially versican $[12,17]$, accumulate in the extracellular matrix (ECM) of the proliferating smooth muscle and recruited macrophage cells, they bind to incoming LDL particles. Electrostatic interaction between the LDL apoB and the sulfated chains on the core PG protein binds the LDL to the cell surface [18] where its solubility is decreased [19]. PG-bound LDL is also more likely to become oxidized, and in either case, the trapped lipoprotein is incorporated into the developing foam cell. Presumably the lipid enters the individual cells by the action of scavenger receptors, but the proponents of this theory do not directly address this element. Despite this omission, the response to retention theory does provide a concrete mechanism for the adherence of circulating lipoproteins to the arterial intima. Therefore, advocates of this theory [16] claim that essentially all later progression can be traced to the initial attraction of circulating LDL to ECM proteoglycans.

The aforementioned lipid infiltration and retention theories provide mechanistic evidence of how lipoproteins can accumulate in the arterial intima, but key steps of atherogenesis are not addressed. Neither theory offers direct evidence for how cholesterol esters form within early foam cells, nor do they explain the initial VSMC proliferation prior to lipid accumulation. Neither theory explains the subsequent entry of monocytes and macrophages to the infiltration region, nor do they explain the predictable locations of lesion development along the arterial tree.

\subsection{Response to injury theory}

The observation that both smooth muscle and macrophage cell types were actively recruited to balloon catheterization sites led to the response to injury hypothesis [20]. According to this theory, the arterial endothelium is compromised by various perturbations such as environmental chemicals, high concentrations of blood lipids, certain types of bacteria and viruses, autoimmunity, and/or hemodynamic stress [21]. In response, the endothelial cells either slough off or become porous, allowing the subsequent lipoproteins and macrophages influx into the arterial intima. Once initial damage has occurred, the exposed intimal cells are increasingly vulnerable to additional hemodynamic and environmental aggravation, thus perpetuating the original injury and eliciting an immune response. Although endothelial denudation or injury is not necessary for foam cell formation, an obvious and observable inflammatory response seems to exacerbate the developing atherosclerotic plaque during the disease's progressive stage.

\subsection{Inflammation theory}

Atherosclerosis is now considered a chronic inflammatory disease [22], largely because signs of inflammation occur concomitantly with hypercholesterolemia [23-26] in a variety of animal models. This inflammation theory proposes that the immune system is activated as a direct result of lipid infiltration $[27,28]$ and so readily explains the presence of monocytes 
and macrophages in the fatty streak. These cells express scavenger receptors that not only ingest lipid, especially oxidized LDL; they actively secrete cytokines and recruit adhesion molecules to the region. These actions are thought to be directly responsible for the increase in extracellular components observed during later stages of atherogenesis [29]. Increasing complexity of the matrix between cells advances opportunities for proteoglycans to bind and transform lipid molecules, thereby perpetuating the entire macrophage recruitment and cytokine signaling process.

In addition to macrophages, endothelial cells, VSMC, and platelets in the developing lesion are all capable of synthesizing and/or releasing chemoattractants and growth factors [9]. These cellular interactions work together to expand the initial fatty streak to a mature, fibrous plaque over time. The inflammatory response is well correlated with plaque stability, and there are already blood tests available that will assess the risk of thrombosis based on the levels of inflammatory markers [30]. However, as with other theories of atherogenesis, the inflammatory response does not account for the initial VSMC proliferation prior to lipid accumulation and macrophage recruitment. Nor does it explain that, in humans, early foam cells are primarily myogenic. For these reasons, the inflammatory theory explains the mechanisms of plaque progression and the likelihood of disease endpoint better than it explains atherogenesis itself.

\subsection{Monoclonal origin theory}

A fourth theory of atherogenesis, that has not gained wide acceptance, states that the VSMC that abnormally proliferate and accumulate lipid are transformed and of monoclonal origin $[31,32]$. The VSMC which develop into foam cells are phenotypically different from their counterparts in the normal media $[33,34]$ in that they actively secrete ECM components such as proteoglycans and collagen [35]. Healthy, fully differentiated VSMC proliferate slowly and do not synthesize an extensive ECM [36]. Loss of cell cycle control and the ability to regulate cholesterol metabolism are early hallmarks of cancerous cells, pathological phenotypes that are seen in atherogenesis. However, technological advances in DNA sequence analyses have confirmed that although VSMC in general are largely heterogenic, subsets of cells involved in atherogenic events are derived from specific clones [37, 38] that seem to proliferate in patches [39]. A second observation that supports this controversial theory is existence of hypo-methylated DNA in atherosclerotic lesions [40]. Decreased methylation is significantly correlated with increases in transcriptional activity. During cancer development, normally silent oncogenes can be expressed because of under methylation [41]. The precise atherogenic role of hypo-methylated DNA and clonal VSMC cells is not determined.

Although the monoclonal origin theory explains the proliferation of an altered population of lipid-accumulating, ECM-producing SMC in the arterial intima, no specific transformation event or set of pathological conditions have been proposed that would account for the initial change in differentiation state, methylation status, and/or the increased mitotic rate in a specific VSMC subpopulation. In addition, animal and human examples in which atherosclerotic lesions appear to regress [42-44], are not readily explained by the monoclonal theory. 


\subsection{Smooth muscle cell phenotypic reversion theory}

Smooth muscle cell differentiation is a complex process that requires multiple transcription factors to be successful [45]. The developing embryo's VSMC are in the synthetic state as they are actively proliferating and synthesizing their contractile elements, myofilaments, and ECM to form the arterial intima [35, 46]. Once the blood vessels are fully formed, the VSMC further differentiate to the contractile state where they stop proliferating and function to facilitate muscle contraction in response to stimuli. A healthy vessel wall is able to maintain both contractility and the quiescent state [34, 47].

During atherogenesis, VSMC seem to revert to the synthetic state where they abnormally produce an extensive ECM [48]. This phenotypic modulation [35] is believed to occur before the cells begin to replicate and migrate to the arterial intima, but the stimulus for this change is unknown. An alternative explanation is that in individuals predisposed to atherosclerosis, the VSMC never fully differentiate. In either case, modified VSMC are characterized by a decrease in the alpha/beta actin isoform ratio [33, 34, 49,50] and the loss of the intermediate filament proteins such as vinculin and desmin $[34,49,50]$. Ongoing efforts have focused on identifying more VSMC phenotypic markers $[36,45,51]$ to clearly define the state of differentiation including elements driving its change [52,53]. Despite the narrow focus on the VSMC role that does not address macrophage recruitment, this idea is a valid attempt to describe the earliest cellular atherogenic events [54].

\subsection{Hemodynamic stress theory}

Hemodynamic stress is a pervasive factor in all atherogenesis theories, because lesions typically develop at aortic regions of bi-directional flow. However, if it were simply a matter of arterial architecture, any organism with a branching aorta would spontaneously develop foam cells and initiate the atherosclerotic pathology. Because this is not the case, there must be some as yet unidentified factor intrinsic to the resistant individuals' vessel wall that can withstand the low shear stress effects while maintaining the cells in a contractile phenotype.

Many theories explain lipid accumulation in the arterial wall, some describe the preferred site of fatty streak formation and the appearance of macrophage cells, but none completely describe the entire series of events that occurs in atherogenesis. Genetic factors clearly influence cholesterol metabolism [55], replication rates [56], the immune response [26, 57] and the mitochondrial oxidative capacity for cellular lipids [58,59], thereby manifesting an underlying influence on all aspects of atherogenesis that warrants additional investigation.

\section{Pigeon model of atherogenesis}

The susceptible-resistant pigeon (Columba livia) model has been employed to understand genetic components of this disease [60]. White Carneau (WC-As) pigeons develop spontaneous atherosclerosis without known risk factors [61, 62]. The pigeon lesions [63, 64], have greater similarities to human atherosclerosis than any other animal model of heart disease. 
St. Clair [65] has reviewed multiple studies clearly demonstrating that WC-As susceptibility resides at the level of the arterial wall. The Show Racer (SR-Ar) pigeon is resistant to the development of atherosclerosis under identical diet and housing conditions, and with similar blood cholesterol levels [61]. Crossbreeding and backcross experiments demonstrated aortic atherosclerosis susceptibility to be inherited in a pattern consistent with an autosomal recessive Mendelian trait [66].

\subsection{Differential gene expression}

Representational Difference Analysis (RDA) was used in reciprocal experiments to identify genes expressed differentially between WC-As and SR-Ar aortic VSMC. Difference products were cloned, sequenced and identified by BLAST against the chicken genome. We found 134 genes with differential expression. An abridged list of the seventy-two transcripts upregulated in WC-As (Table 1) included caveolin (CAV1) and enolase (ENO1). CAV1, reported as WAG-65N20 Clone, was not yet annotated in the original analysis. Its subsequent identification was crucial data because CAV1 represented the biggest difference between breeds. Lumican (LUM) and cytochrome $b$ (CYTB) were among the sixty-two genes upregulated in the SR-Ar. The abridged list is shown in Table 2.

We originally placed each individual transcript in 6 thematic metabolic pathways using the Kyoto Encyclopedia of Genes and Genomes (KEGG) [67] and Pathway Studio [68]. These included energy metabolism, VSMC phenotype, transcriptional regulation, translational regulation, cell signaling, and an immune response. Energy metabolism and contractility pathways exhibited the most striking disparity. Genes associated with glycolysis and a synthetic VSMC phenotype were expressed in WC-As cells whereas SR-Ar cells expressed genes indicative of oxidative phosphorylation and a contractile VSMC phenotype. In WC-As cells, the alternatives of insufficient ATP production limiting contractile function or the lack of functional contractile elements down-regulating ATP synthesis cannot be distinguished due to the compressed in-vitro versus in-vivo developmental time frame. However, the genetic potential for effectively coupling energy production to muscle contraction present in the resistant SR-Ar was lacking in the susceptible WC-As [69, 70].

For this review, we employed the Metacore database [71] from GeneGo (Carlsbad, CA) to automatically place genes into networks according to their biological function and known interactions. Monosaccharide catabolism, translation, and multicellular organism development were the most significant biological processes operating in the WC-As VSMC (Table 3). Monosaccharide catabolism was represented by ENO1, lactate dehydrogenase A (LDHA), transketolase (TKT1), and glucose-phosphate isomerase (GPI). Fourteen genes involved in translation were upregulated in our experiment including ribophorin (RPN1), Ligatin (LGTN), and a number of ribosomal proteins. Although many genes participate in multicellular organism development, 46 were upregulated in the WC-As including cyclin D (CCND2), annexin (ANXA2), collagen (COL5A2), beta actin (ACTB), vimentin (VIM), transmembrane protein 126a (TMEM126A), subunit 3 of the 26S Proteasome ATPase (PSMC3) and diacylglycerol O-acetyltransferase (DGAT2). 


\begin{tabular}{|c|c|c|c|}
\hline Gene Product & Gene & WC-As copies & SR-Ar copies \\
\hline Caveolin-1 & CAV1 & 39 & 1 \\
\hline Enolase, alpha & ENO1 & 30 & 0 \\
\hline Retinol binding protein 7 & RBP7 & 19 & 2 \\
\hline Cleavage \& polyadenylation specific factor 2 & CPSF2 & 18 & 0 \\
\hline Mitochondrial ribosomal protein L27 & MRPL27 & 18 & 0 \\
\hline N-acetyltransferase 13 (aka MAK3) & NAT13 & 18 & 0 \\
\hline Ribophorin I & RPN1 & 16 & 0 \\
\hline Stromal cell-derived factor 1 (aka SDF-1) & $\mathrm{CXCL} 12$ & 16 & 2 \\
\hline Diacylglycerol O-acetyltransferase 2 & DGAT2 & 14 & 0 \\
\hline 26S Proteasome ATPase Subunit 2 & PSMC2 & 14 & 0 \\
\hline Ribosomal Protein Large Subunit 32 & RPL32 & 9 & 0 \\
\hline Actin, beta & ACTB & 9 & 1 \\
\hline Dachshund homolog-1c & DACH1 & 9 & 1 \\
\hline Annexin A2 & ANXA2 & 8 & 0 \\
\hline Ligatin & LGTN & 8 & 0 \\
\hline Sec61 alpha & SEC61A & 8 & 2 \\
\hline Transketolase & TKT1 & 6 & 0 \\
\hline Collagen, alpha-2 type I & COL1A2 & 6 & 1 \\
\hline Aldehyde dehydrogenase E3 & ALDH9A1 & 5 & 1 \\
\hline Solute carrier protein 25/A6 (ATP/ADP antiporter) & SLC25A6 & 5 & 3 \\
\hline Nucleoside diphosphate kinase & CNDPK & 4 & 0 \\
\hline TNF-alpha induced protein 8 & TNFAIP8 & 4 & 0 \\
\hline Lactate dehydrogenase subunit A & LDHA & 3 & 0 \\
\hline Macrophage erythroblast attacher & MAEA & 3 & 0 \\
\hline 26S Proteasome ATPase Subunit 3 & PSMC3 & 3 & 0 \\
\hline Spondin 1 & SPON1 & 3 & 0 \\
\hline Transmembrane protein 167 & TMEM167 & 3 & 0 \\
\hline Decorin (dermatan sulfate PG) & DCN & 2 & 0 \\
\hline
\end{tabular}

Table 1. Genes with the highest differential expression in White Carneau (WC-As) vascular smooth muscle cells (VSMC) in representational difference analysis abridged from [70]. 


\begin{tabular}{|c|c|c|c|}
\hline Gene Product & Gene & WC-As copies & SR-Ar copies \\
\hline Ribosomal Protein Large Subunit 3 & RPL3 & 6 & 73 \\
\hline Lumican Precursor (keratan sulafate PG) & LUM & 2 & 47 \\
\hline Cytochrome b & CYTB & 0 & 41 \\
\hline Fibulin-5 precursor (aka DANCE) & FBLN5 & 0 & 30 \\
\hline Fbronectin type 1 & FN1 & 0 & 29 \\
\hline Cytochrome Oxidase Subunit II & COII & 11 & 28 \\
\hline Lactate dehydrogenase subunit B & LDHB & 21 & 25 \\
\hline Peroxiredoxin 1 & PRDX1 & 8 & 20 \\
\hline NADH subunit 4 & ND4 & 4 & 19 \\
\hline Eukaryotic translation initiation factor $4 \mathrm{~A} 2$ & EIF4A2 & 8 & 19 \\
\hline SMC Myosin Heavy Chain 11 & MYH11 & 0 & 12 \\
\hline Proteosome maturation factor UMP1 & POMP & 6 & 10 \\
\hline Tropomyosin, alpha & TPM1 & 0 & 9 \\
\hline 26S Proteasome Regulatory Lid (non ATPase) & PSMD1 & 0 & 8 \\
\hline Myosin light chain kinase; telokin & MYLK & 0 & 7 \\
\hline Actin, alpha-2 & ACTA2 & 0 & 6 \\
\hline Coactosin-like 1 & COTL1 & 0 & 5 \\
\hline Cytochrome Oxidase Subunit I & $\mathrm{COI}$ & 0 & 5 \\
\hline Mariner 1 transposase gene (similar to) & SETMAR & 0 & 3 \\
\hline RAS oncogene family (GTP binding) & RAB1A & 0 & 3 \\
\hline Sec61 gamma & SEC61G & 0 & 3 \\
\hline Squalene epoxidase & SQLE & 0 & 3 \\
\hline Ribosomal Protein Small Subunit 8 & RPS8 & 1 & 3 \\
\hline F0-ATP synthase subunits $6 \& 8$ & ATP6/8 & 2 & 3 \\
\hline Fatty acid binding protein 4 & FABP4 & 2 & 3 \\
\hline Prohibitin 2 (aka B-cell receptor protein 37) & PHB2 & 2 & 3 \\
\hline Activin A/TGFB Receptor 1 & ACVR1 & 0 & 2 \\
\hline Fumarate hydratase/fumarase & $\mathrm{FH}$ & 0 & 2 \\
\hline 26S Proteasome ATPase Subunit 4 & PSMC1 & 0 & 2 \\
\hline
\end{tabular}

Table 2. Genes with the highest differential expression in Show Racer (SR-Ar) vascular smooth muscle cells (VSMC) in representational difference analysis abridged from [70]. 


\begin{tabular}{|c|c|c|}
\hline Biological Process & $\begin{array}{l}\text { Ratio of significant expressed genes } \\
\text { from total number of genes involved in } \\
\text { process }\end{array}$ & P-value \\
\hline monosaccharide catabolic process & $8 / 91$ & 4.737E-09 \\
\hline Translation & $14 / 452$ & 6.498E-09 \\
\hline multicellular organismal development & $46 / 4895$ & 6.897E-09 \\
\hline glucose catabolic process & $7 / 69$ & $1.657 \mathrm{E}-08$ \\
\hline system development & $41 / 4195$ & 2.773E-08 \\
\hline alcohol catabolic process & $8 / 114$ & $2.834 \mathrm{E}-08$ \\
\hline developmental process & $47 / 5334$ & $3.512 \mathrm{E}-08$ \\
\hline \multicolumn{3}{|c|}{ establishment of protein localization in endoplasmic } \\
\hline reticulum & $8 / 119$ & $3.970 \mathrm{E}-08$ \\
\hline protein targeting to $\mathrm{ER}$ & $8 / 119$ & $3.970 \mathrm{E}-08$ \\
\hline anatomical structure development & $473 / 4620$ & $4.356 \mathrm{E}-08$ \\
\hline
\end{tabular}

Table 3. Biological processes (GeneGo, Carlsbad, CA) upregulated in White Carneau (WC-As) vascular smooth muscle cells (VSMC) based on representational difference analysis.

The most relevant network from the dataset connects 8 identified genetic transcripts (Figure 1) including the extracellular signals decorin (DCN), and chemokine ligand 12 (CXCL12), the cytoskeletal components ezrin (VIL2), ACTB, and PSMC3, as well as the nuclear transcripts ENO1, CCND2, and daschund homoglog 1c (DACH1). The expression of ENO1, a glycolytic enzyme and a transcription factor, is promoted by three separate network factors. First, its expression is influenced by DACH1 directly. Second, ENO1 is activated indirectly by CXCL12, where it works through c-src (not in dataset) and ACTB. Finally, DCN, by way of talin (not in dataset) also activates ACTB. Once expressed, ENO1 participates generally in monosaccharide catabolism and specifically accelerates cell proliferation via CCND2.

Smooth muscle contraction and myofibril assembly were the most significant biological processes in the SR-Ar VSMC (Table 4). These pathways included alpha actin (ACTA2), myosin heavy chain (MYH11), tropomyosin (TPM1) and the telekin transcript from myosin light chain kinase (MYLK). There were also major differences in cellular component organization between the two breeds, with the SR-Ar expressing not only MYH11, but LUM, fibronectin (FN1), high mobility group transcription factor (HMG1), and activin 1, a receptor for transforming growth factor beta (TGF1), among many others.

The Figure 2 network depicts the critical nature of SP1, a transcription factor known to regulate VSMC differentiation by turning on the gene for myosin heavy chain [73]. Although SP1 was not found in our experiment, a required cofactor, CRSP2, was upregulated in the SR-Ar. SP1 also appears to influence alpha actin (ACTA2) activity. ACTA2, expressed in contractile VSMC of SR-Ar does not seem to influence transcription as does the beta isoform, which is associated with the synthetic phenotype found in Wc-As. 


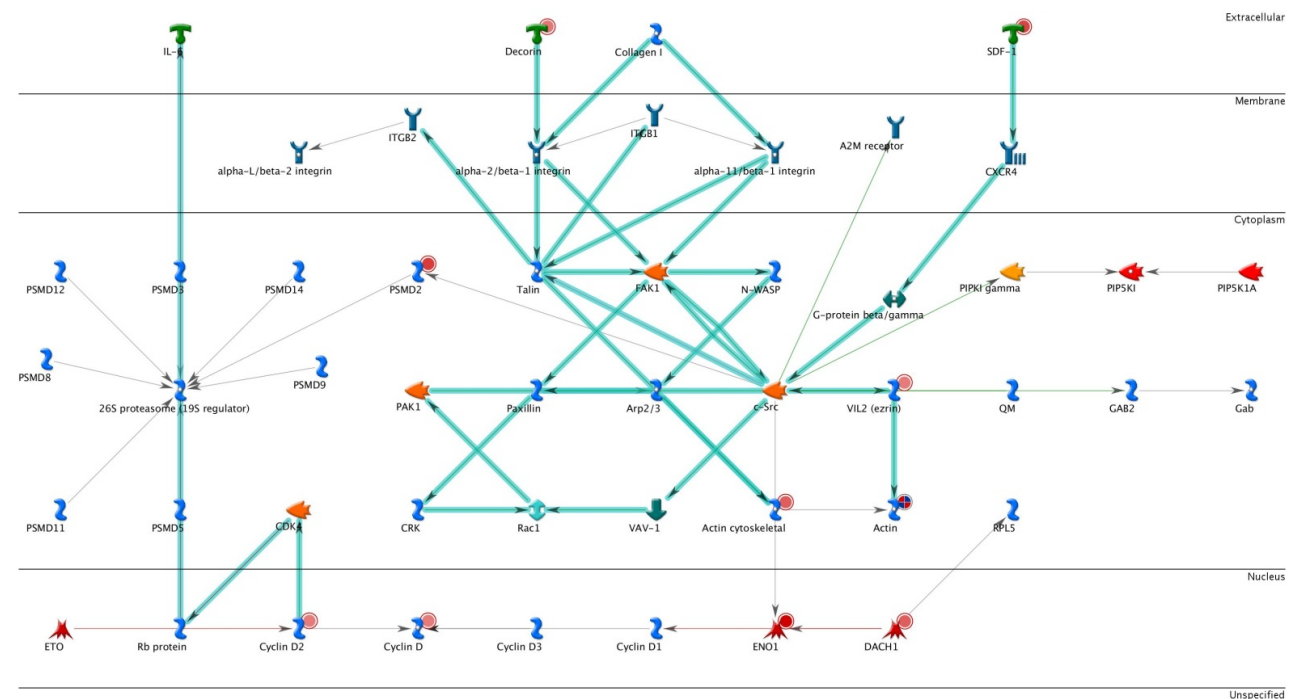

Figure 1. Network analysis (GeneGo, Carlsbad, CA) incorporating genes upregulated in White Carneau (WC-As) vascular smooth muscle cells (VSMC) based on representational difference analysis. Abbreviations listed in [72].

\begin{tabular}{lcc}
\hline Biological Process & $\begin{array}{c}\text { Ratio of signifcant expressed } \\
\text { genes from total number of } \\
\text { genes involved in process }\end{array}$ & P-value \\
\hline smooth muscle contraction & $12 / 76$ & $2.981 \mathrm{E}-17$ \\
\hline muscle contraction & $14 / 258$ & $2.311 \mathrm{E}-13$ \\
\hline myofibril assembly & $9 / 64$ & $1.004 \mathrm{E}-12$ \\
\hline muscle system process & $14 / 305$ & $2.247 \mathrm{E}-12$ \\
\hline cellular component organization at cellular level & $38 / 3480$ & $3.841 \mathrm{E}-12$ \\
\hline skeletal myofibril assembly & $6 / 14$ & $4.050 \mathrm{E}-12$ \\
\hline actomyosin structure organization & $9 / 76$ & $1.144 \mathrm{E}-11$ \\
\hline cellular component organization or biogenesis at cellular level & $38 / 3604$ & $1.199 \mathrm{E}-11$ \\
\hline cellular catabolic process & $28 / 1908$ & $1.270 \mathrm{E}-11$ \\
\hline muscle tissue development & $14 / 347$ & \\
\hline
\end{tabular}

Table 4. Biological processes (GeneGo, Carlsbad, CA) upregulated in Show Racer (SR-Ar) vascular smooth muscle cells (VSMC) based on representational difference analysis. 


\subsection{Differential protein expression}

DNA transcripts of a species do not directly reveal the protein complexity of that organism [74]. A more complete elucidation of gene expression can be achieved through characterization of the proteins, the biological determinants of phenotype. Towards that goal, soluble proteins in aortic smooth muscle cells cultured from WC-As and SR-Ar pigeons were extracted and separated on two-dimensional electrophoresis gels.

Proteins differentially-expressed were arrayed on a map, plotting molecular weight against isoelectric point (pI). Eight discrete zones were identified, five which included proteins unique to susceptible cells and three which included proteins unique to resistant cells. Of the 88 differentially-expressed proteins from WC-As cells, 41 were located in unique zones while 29 of 82 differentially-expressed proteins from Sr-Ar cells were in unique zones. Selected proteins from susceptibility and resistance zones were annotated by peptide mass fragments, molecular weights, pIs, and correspondence with genes differentially-expressed between cells from the two breeds. Eight proteins were unique to the WC-As, and eight proteins were exclusively expressed in the SR-Ar (Table 5). Some of the annotated proteins included smooth muscle myosin phosphatase (MYPT1), myosin heavy chain (MYH11) -and fatty acid binding protein (FABP) in the SR-Ar. Ribophorin (RPN1), heat shock protein (HSP70), cyclin (CCND2) and TNF $\alpha$-inducing factor (TNF) were found in WC-As [75]. Ribophorin, cyclin, TNF $\alpha$ Induced Protein 8, FABP and MYH11 were also differentially expressed in the RDA experiments and are likely important to the atherosclerotic phenotype in pigeon VSMC.

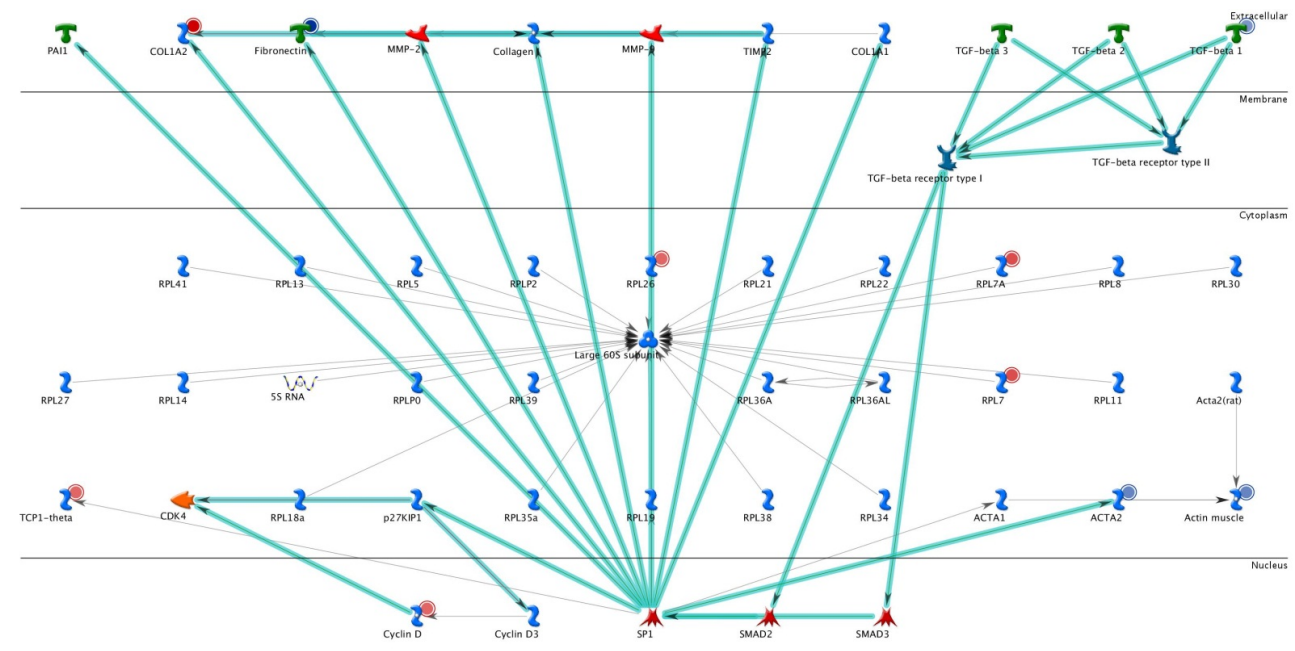

Figure 2. Network analysis (GeneGo, Carlsbad, CA) incorporating genes upregulated in Show Racer (SR-Ar) vascular smooth muscle cells (VSMC) based on representational difference analysis. Abbreviations listed in [72]. 


\begin{tabular}{|c|c|c|}
\hline Protein & Name & Breed \\
\hline Heat shock protein & HSP70 & WC-As \\
\hline Tumor necrosis factor alpha inducing factor & TNF & WC-As \\
\hline Mannosidase & MAN2BA & WC-As \\
\hline Tropomyosin & TPM1 & WC-As \\
\hline Cyclin & CCND2 & WC-As \\
\hline Lumican & LUM & WC-As \\
\hline Ribophorin & RPN1 & WC-As \\
\hline Inhibitor of kappa light polypeptide enhancer in B cells & IKBKAP & WC-As \\
\hline Serine threonine kinase & STK & SR-Ar \\
\hline Smooth muscle myosin phosphatase & MYPT1 & SR-Ar \\
\hline Activin binding protein & FST & SR-Ar \\
\hline Myosin heavy chain & MHY11 & SR-Ar \\
\hline Serine threonine protein kinase & STK24 & SR-Ar \\
\hline Phosphoglucomutase & PGM & SR-Ar \\
\hline Fatty acid binding protein & FABP & SR-Ar \\
\hline Peroxiredoxin & PRDX1 & SR-Ar \\
\hline
\end{tabular}

Table 5. Annotated differentially-expressed soluble proteins extracted from vascular smooth muscle cells (VSMC) of White Carneau (WC-As) and Show Racer (SR-Ar) pigeons abridged from [75].

All 16 annotated proteins were entered into GeneGo (Carlsbad, CA) to elucidate the metabolic networks operating in each breed. In the WC-As, regulation of molecular function, regulation of inclusion body assembly, and response to unfolded protein were the most significant biological processes (Table 6). Heat shock protein contributed to each of these processes, and was joined by CCND2, TPM1, TNF, and inhibitor of kappa light polypeptide enhancer in $\mathrm{B}$ cells (IKBKAP) in overall regulation of molecular function. In addition to those mentioned previously, TPM1 and IKBKAP were also differentially expressed in the RDA experiments. The major biological processes operating in the SR-Ar were myosin thick filament assembly and organization (Table 7), represented primarily by the proteins MHY11 and MYPT1. This was similar to the RDA experiment, where smooth muscle contraction and myofibril assembly were indicated by multiple genetic transcripts. 


\begin{tabular}{lcc}
\hline Biological Process & $\begin{array}{c}\text { Ratio of significant expressed } \\
\text { genes from total number of } \\
\text { genes involved in process }\end{array}$ & P-value \\
\hline negative regulation of inclusion body assembly & $3 / 5$ & $1.604 \mathrm{E}-09$ \\
\hline regulation of molecular function & $11 / 2707$ & $5.827 \mathrm{E}-09$ \\
\hline regulation of inclusion body assembly & $3 / 8$ & $8.975 \mathrm{E}-09$ \\
\hline response to unfolded protein & $5 / 156$ & $2.053 \mathrm{E}-08$ \\
\hline response to topologically incorrect protein & $5 / 162$ & $2.481 \mathrm{E}-08$ \\
\hline regulation of catalytic activity & $10 / 2242$ & $2.507 \mathrm{E}-08$ \\
\hline regulation of cellular component biogenesis & $6 / 379$ & $3.864 \mathrm{E}-08$ \\
\hline negative regulation of myeloid cell apoptosis & $3 / 13$ & $4.576 \mathrm{E}-08$ \\
\hline pegative regulation of vasoconstriction & $3 / 14$ & $5.822 \mathrm{E}-08$ \\
\hline
\end{tabular}

Table 6. Biological processes (GeneGo, Carlsbad, CA) upregulated in proteomic analysis of White Carneau (WC-As) vascular smooth muscle cells (VSMC).

\begin{tabular}{lcc}
\hline Biological Process & $\begin{array}{c}\text { Ratio of significant expressed } \\
\text { genes from total number of } \\
\text { genes involved in process }\end{array}$ & P-value \\
\hline skeletal muscle myosin thick filament assembly & $4 / 8$ & $3.53 \mathrm{E}-12$ \\
\hline striated muscle myosin thick filament assembly & $4 / 8$ & $3.53 \mathrm{E}-12$ \\
\hline myosin filament assembly & $4 / 11$ & $1.66 \mathrm{E}-11$ \\
\hline cardiac muscle fiber development & $4 / 11$ & $1.66 \mathrm{E}-11$ \\
\hline elastic fiber assembly & $4 / 11$ & $1.66 \mathrm{E}-11$ \\
\hline myosin filament organization & $4 / 11$ & $1.66 \mathrm{E}-11$ \\
\hline skeletal myofibril assembly & $4 / 14$ & $5.04 \mathrm{E}-11$ \\
\hline extracellular matrix assembly & $4 / 14$ & $5.04 \mathrm{E}-11$ \\
\hline myofibril assembly & $4 / 64$ & $3.15 \mathrm{E}-08$ \\
\hline actomyosin structure organization & $4 / 76$ & $6.34 \mathrm{E}-08$ \\
\hline
\end{tabular}

Table 7. Biological processes (GeneGo, Carlsbad, CA) upregulated in proteomic analysis of Show Racer (SR-Ar) vascular smooth muscle cells (VSMC).

The major network operating in the protein data set is depicted in Figure 3. This network shows the cellular signaling cascade initiated by the cytokine TNF $\alpha$. Although TNF $\alpha$ itself was not found in either experiment, its activity is suggested by the induced factors expressed in the WC-As. The transcription factors c-Jun and Ap-1 activate TNF $\alpha$, which then 
induces JAK1 gene expression via two receptors, TNFR1 and TNFR2. JAK1 turns on STAT1 and this pathway is known to regulate VSMC inflammatory processes [76]. TNF $\alpha$ also exerts its biological effect on apoptotic peptidase activating factor 1 (Apaf-1), which induces apoptosis via TRADD and the cellular caspases. This would be a simple story of inflammation and apoptosis, if it wasn't for the concomitant HSP70 expression in the WC-As. This heat shock protein also works through JAK1, but has an inhibitory effect on Apaf-1 [77]. Therefore, although Apaf-1 expression is stimulated by c-Jun, both via TNF $\alpha$ and cytochrome c, HSP70 simultaneously blocks Apaf-1, possibly causing problematic cells to resist apoptosis and continue to proliferate. This pathway is not present in the SR-Ar.

\section{Relevance to atherogenic theories}

The idea that susceptible and resistant populations exhibit differences in VSMC differentiation is vigorously supported by our data. Both experiments showed SR-Ar VSMC to be in the contractile phase, while this was clearly not the case for WC-As. The WC-As did not express myosin-related genes or proteins, and the presence of beta actin correlates with a synthetic phenotype. Contractility was a major difference in our previous gene analysis [70], so finding related proteins strengthens this pathway's relevance to the resistant phenotype. Contraction depends on the ATP produced by oxidative phosphorylation. Although mitochondrial respiration was a significant biological process in this analysis, monosaccharide catabolism was upregulated in the WC-As.

Glycolytic enzymes ENO1 and lactate dehydrogenase A (LDHA), both found in the WC-As, contain hypoxia response elements [78]. This may indicate that during oxygen deficit, VSMC shift their energy production from oxidative phosphorylation, which has an absolute oxygen requirement, to glycolysis, which is anaerobic. Glycolysis does not produce enough ATP to support a contractile phenotype, and the upregulation of ENO1 to support glycolysis would be problematic, given its dual role as a transcription factor (Figure 1). In the absence of oxygen, lipids cannot be fully oxidized which could have a two-fold effect. First, more substrate is available for cholesterol and TAG synthesis, an idea supported by DGAT2 expression in the WC-As. Second, the increased ROS generation from partially-oxidized lipids could be triggering the observed WC-As inflammatory pathway.

The theory that atherosclerosis is a chronic inflammatory disease is supported by the data sets, although the chemokines expressed in the WC-As are secondary indicators of inflammation, and the primary mediator remains unclear. In addition to the TNF alpha pathway uncovered in the WC-As proteomics experiment (Figure 3), CXCL12 was significantly upregulated in the RDA experiments. This is relevant to the human disease as it was recently identified as a CVD- susceptibility locus in a genome wide association study [79, 80]. Although newly implicated in atherosclerosis, CXCL12 is thought to exacerbate the probability of plaque rupture during the advanced stages of the disease [81]. The over-expression of CXCL12 in the earliest stages of atherogenesis is an important observation in the WC-As, especially given that it activates c-src (Figure 1). As described earlier in this review, c-src acti- 
vates beta actin (synthetic phenotype) and enolase (glycolytic enzyme), and, like ENO1, CXCL12 has a hypoxia response element in its promoter [82]. CXCL12 has been implicated in the metastasis and angiogenesis of some cancers, and is an "independent predictor" of ovarian cancer survival rates [83]. In this capacity, it may contribute to the migration and proliferation of VSMC that occur early in atherogenesis.

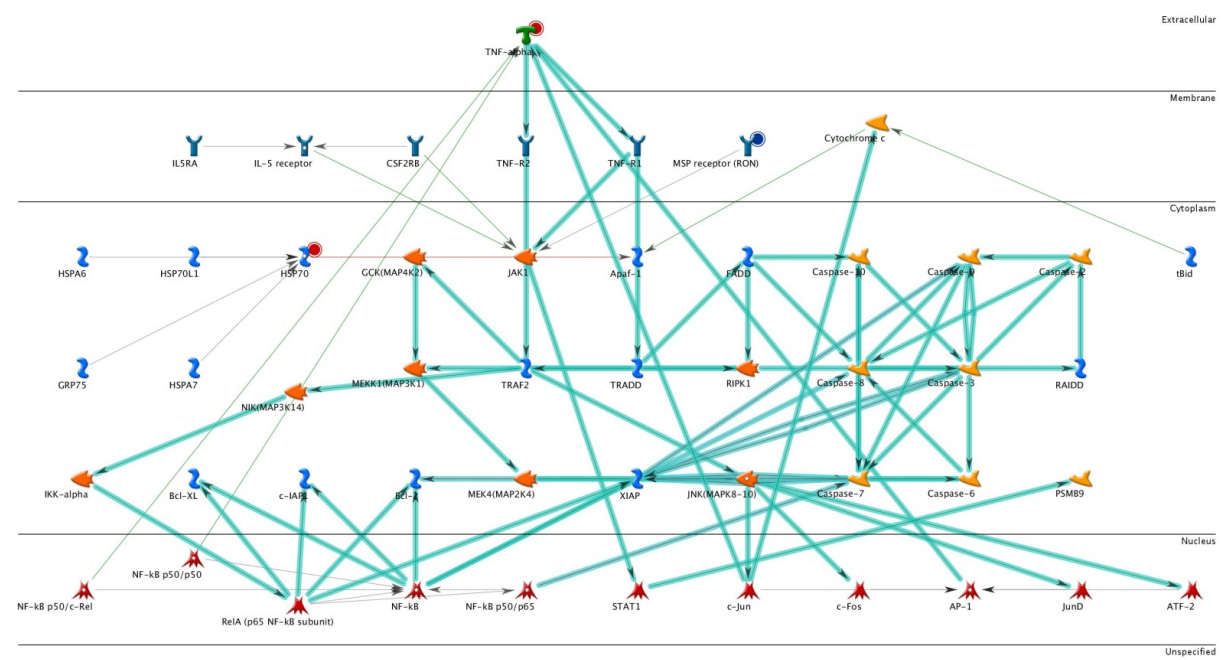

Figure 3. Network analysis (GeneGo, Carlsbad, CA) incorporating annotated differentially-expressed soluble proteins extracted from vascular smooth muscle cells (VSMC) of White Carneau (WC-As) and Show Racer (SR-Ar) pigeons. Abbreviations listed in [72].

The response to retention theory is marginally supported by the data. Ribophorin and mannosidase expression in both experiments suggests increased glycosylation in the WC-As, a prerequisite of lipid retention. Lipid retention was further suggested by the expression of CAV1 in the WC-As. This finding is important because APOE knockout mice studies have shown that the loss of CAV1 is actually protective against atherosclerosis [84]. Therefore, its differential expression in the pigeon model may play an important role in the susceptible/ resistant phenotypes. Finally, the response to injury, monoclonal nature, and the effect of hemodynamic stress were not tested in either experiment, so their contribution to atherosclerosis in the pigeon model could not be determined.

Gene and protein expression in susceptible and resistant pigeon VSMC support current theories of human atherogenesis. Many genetic factors have been identified that contribute to plaque progression, but the gene or genes responsible for initiation of the disease remain unclear. The autosomal inheritance of spontaneous atherosclerosis in the White Carneau suggests that the affected gene is one having broad effects, such as a transcription factor. Because pigeon VSMC genes and proteins are differentially expressed prior to foam cell formation, the pigeon is a valuable model for studying the earliest events of atherogenesis. 


\section{Acknowledgements}

Partial funding was provided by the New Hampshire Agricultural Experiment Station. This is Scientific Contribution Number 2490.

\section{Author details}

J. L. Anderson, S. C. Smith and R. L. Taylor Jr.

University of New Hampshire, Durham, NH, USA

\section{References}

[1] Breslow JL. Genetic differences in endothelial cells may determine atherosclerosis susceptibility. Circulation 2000; 102(1) 5-6.

[2] Allayee H, Ghazalpour A, Lusis AJ. Using mice to dissect genetic factors in atherosclerosis. Arteriosclerosis Thrombosis and Vascular Biology 2003; 23(9) 1501-1509.

[3] Munro J, Cotran R. The pathogenesis of atherosclerosis: atherogenesis and inflammation. Laboratory Investigation 1988; 58(3) 249-261.

[4] Mosse P, Campbell G, Campbell J. Smooth muscle phenotypic expression in human carotid arteries. II. Atherosclerosis-free diffuse intimal thickenings compared with the media. Arteriosclerosis, Thrombosis and Vascular Biology 1986; 6(6) 664-669.

[5] Mosse P, Campbell G, Wang Z, Campbell J. Smooth muscle phenotypic expression in human carotid arteries. I. Comparison of cells from diffuse intimal thickenings adjacent to atheromatous plaques with those of the media. Laboratory Investigation 1985; 53(5) 556-562.

[6] Davies P. Vascular cell interactions with special reference to the pathogenesis of atherosclerosis. Laboratory Investigation 1986; 55(1), 5-24.

[7] Ross R. The pathogenesis of atherosclerosis-an update. New England Journal of Medicine 1986; 314(8) 488-500.

[8] Stary H. Evolution and progression of atherosclerotic lesions in coronary arteries of children and young adults. Arteriosclerosis, Thrombosis and Vascular Biology 1989; 9(1 Suppl) I19-32.

[9] Wissler RW, Hiltscher L, Oinuma T, and the PDAY Research Group. The lesions of atherosclerosis in the young: from fatty streaks to intermediate lesions. In: Fuster V, Ross R, Topol EJ. (eds). Atherosclerosis and Coronary Artery Disease. New York: Lippincott-Raven Press; 1996. p475-489. 
[10] Steinberg D. A critical look at the evidence for the oxidation of LDL in atherogenesis. Atherosclerosis 1997; 131(Suppl 1) S5-S7.

[11] Wustner D, Mondal M, Tabas I, Maxfield F. Direct observation of rapid internalization and intracellular transport of sterol by macrophage foam cells. Traffic $2005 ; 6(5)$ 396-412.

[12] Khalil MF, Wagner WD, Goldberg IJ. Molecular interactions leading to lipoprotein retention and the initiation of atherosclerosis. Arteriosclerosis Thrombosis and Vascular Biology 2004; 24(12) 2211-2218.

[13] Niinioski J, Heughan C, Hunt T. Oxygen tensions in the aortic wall of normal rabbits. Atherosclerosis 1973; 17(3) 353-359.

[14] Bernal-Mizrachi C, Gates AC, Weng S, Imamura T, Knutsen RH, DeSantis P, Coleman T, Townsend RR, Muglia LJ, Semenkovich CF. Vascular respiratory uncoupling increases blood pressure and atherosclerosis. Nature 2005; 435(7041) 502-506.

[15] Chobanian AV, Manzur F. Metabolism of lipid in the human fatty streak lesion. Journal of Lipid Research 1972; 13(2) 201-206.

[16] Williams KJ, Tabas I. The response-to-retention hypothesis of early atherogenesis. Arteriosclerosis, Thrombosis and Vascular Biology 1995; 15(5) 551-561.

[17] O'Brien KD, Olin KL, Alpers CE, Chiu W, Ferguson M, Hudkins K, Wight TN, Chait A. Comparison of apolipoprotein and proteoglycan deposits in human coronary atherosclerotic plaques: colocalization of biglycan with apolipoproteins. Circulation 1998; 98(6) 519-527.

[18] Skalen K, Gustafsson M, Rydberg EK, Hulten LM, Wilkund O, Innerarity TL, Boren J. Subendothelial retention of atherogenic lipoproteins in early atherosclerosis. Nature 2002; 417(6890) 750-754.

[19] Pentikainen MO, Lehtonen EMP, Oorni K, Lusa S, Somerharju P, Jauhiainen M, Kovanen PT. Human arterial proteoglycans increase the rate of proteolytic fusion of low density lipoprotein particles. Journal of Biological Chemistry 1997; 272(40) 25283-25288.

[20] Ross R, Glomset JA. Atherosclerosis and the arterial smooth muscle cell. Science 1973; 180(4093) 1332-1339.

[21] Reardon CA, Getz GS. Mouse models of atherosclerosis. Current Opinion in Lipidology 2001; 12(2) 167-173.

[22] Ridker P. New clue to an old killer: inflammation and heart disease. Nutrition Action 2000; 27(7) 3-5.

[23] Rong JX, Shen L, Chang YH, Richters A, Hodis HN, Sevanian A. Cholesterol oxidation products induce vascular foam cell lesion formation in hypercholesterolemic New Zealand white rabbits. Arteriosclerosis, Thrombosis and Vascular Biology 1999; 19(9) 2179-2188. 
[24] Libby P, Ridker PM, Maseri A. Inflammation and atherosclerosis. Circulation 2002; 105(9) 1135-1143.

[25] Steinberg D. Atherogenesis in perspective: hypercholesterolemia and inflammation as partners in crime. Nature Medicine 2002; 8(11) 1211-1217.

[26] Hansson G, Libby P. The immune response in atherosclerosis: a double-edged sword. Nature Reviews Immunololgy 2006; 6(7) 508-519.

[27] Rong JX, Shapiro M, Trogan E, Fisher EA. Transdifferentiation of mouse aortic smooth muscle cells to a macrophage-like state after cholesterol loading. Proccedings of the National Academy of Sciences USA 2003; 100(23) 13531-13536.

[28] Ruberg FL, Loscalzo J. Inflammation and atherothrombosis. In: Loscalzo J. (ed.) Molecular Mechanisms of Atherosclerosis. Abingdon, Oxon: Taylor and Francis; 2005. p. 45-60.

[29] Tedgui A, Mallat Z. Cytokines in atherosclerosis: pathogenic and regulatory pathways. Physiological Reviews 2006; 86(2) 515-581.

[30] Gibbons GH, Liew CC, Goodarzi MO, Rotter JI, Hsueh WA, Siragy HM, Pratt R, Dzau V.J. Genetic markers: progress and potential for cardiovascular disease. Circulation 2004; 109(25 Suppl 1) 47-58.

[31] Benditt EP. Evidence for a monoclonal origin of human atherosclerotic plaques and some implications. Circulation 1974; 50(4) 650-652.

[32] Virmani R, Kolodgie FD, Burke AP, Farb A, Schwartz S.M. Lessons from sudden coronary death: a comprehensive morphological classification scheme for atherosclerotic lesions. Arteriosclerosis, Thrombosis and Vascular Biology 2000; 20(5) 1262-1275.

[33] Gabbiani G, Kocher O, Bloom WS. Actin expression in smooth muscle cells of rat aortic intimal thickening, human atheromatous plaque, and cultured rat aortic media. Journal of Clinical Investigation 1984; 73(1) 148-152.

[34] Schwartz SM, Campbell GR, Campbell JH. Replication of smooth muscle cells in vascular disease. Circulation Research 1986; 58(4) 427-444.

[35] Thyberg J, Hedin U, Sjolund M, Palmberg L, Bottger B. Regulation of differentiated properties and proliferation of arterial smooth muscle cells. Arteriosclerosis, Thrombosis and Vascular Biology 1990; 10(6) 966-990.

[36] Owens GK. Role of alterations in the differentiated state of smooth muscle cell in atherogenesis. In: Fuster V, Ross R, Topol EJ. (eds). Atherosclerosis and Coronary Artery Disease. New York: Lippincott-Raven Press; 1996. p401-420.

[37] Schwartz SM, Murry CE. Proliferation and the monoclonal origins of atherosclerotic lesions. Annual Review of Medicine 1998; 49 437-460.

[38] Doherty TM, Shah PK, Rajavashisth TB. Cellular origins of atherosclerosis: towards ontogenetic endgame?. FASEB Journal 2003; 7(6) 592-597. 
[39] Zalewski A, Shi Y, Johnson AG. Diverse origin of intimal cells: smooth muscle cells, myofibroblasts, fibroblasts, and beyond? Circulation Research 2002; 91(8) 652-655.

[40] Hiltunen MO, Turunen MP, Häkkinen TP, Rutanen J, Hedman M, Mäkinen K, Turunen A, Aalto-Setalä K, Ylä-Herttuala S. DNA hypomethylation and methyltransferase expression in atherosclerotic lesions. Vascular Medicine 2002; 7(1) 5-11.

[41] Kaneda A, Takai D, Kaminishi M, Okochi E, Ushijima T. Methylation-sensitive representational difference analysis and its application to cancer research. Annals of the New York Academy of Sciences 2003; 983(2) 131-141.

[42] Malinow M. Experimental models of atherosclerosis regression. Atherosclerosis 1983; 48(2) 105-118.

[43] Hadjiisky P, Bourdillon M, Grosgogeat Y. Natural history of the regression of atherosclerosis: from animal models to men. Archive Mal Coeur Vaiss 1988; 81(11) 1411-1417.

[44] Harris JD, Graham IR, Schepelmann S, Stannard AK, Roberts ML, Hodges BL, Hill V, Amalfitano A, Hassall DG, Owen JS, Dickson G. Acute regression of advanced and retardation of early aortic atheroma in immunocompetent apolipoprotein-E (apoE) deficient mice by administration of a second generation [E1-, E3-, polymerase-] adenovirus vector expressing human apoE. Human Molecular Genetics 2002; 11(1) 43-58.

[45] Owens GK, Kumar MS, Wamhoff BR. Molecular regulation of vascular smooth muscle cell differentiation in development and disease. Physiological Reviews 2004; 84 (3) $767-801$.

[46] Tyson KL, Weissberg PL, Shanahan CM. Heterogeneity of gene expression in human atheroma unmasked using cDNA representational difference analysis. Physiological Genomics 2002; 9(2) 121-130.

[47] Gizard F, Amant C, Barbier O, Bellosta S, Robillard R, Percevault F, Sevestre H, Krimpenfort P, Corsini A, Rochette J, Glineur C, Fruchart JC, Torpier G, Staels B. PPAR \{alpha\} inhibits vascular smooth muscle cell proliferation underlying intimal hyperplasia by inducing the tumor suppressor p16INK4a. Journal of Clinical Investigation 2005;115(11) 3228-3238.

[48] Campbell J, Popadynec L, Nestel P, Campbell G. Lipid accumulation in arterial smooth muscle cells. Influence of phenotype. Atherosclerosis 1983; 47(3) 279-295.

[49] Worth NF, Campbell GR, Rolfe BE. A role for rho in smooth muscle phenotypic regulation. Annals of the New York Academy of Sciences 2001; 947() 316-322.

[50] Worth N, Rolfe B, Song J, Campbell G. Vascular smooth muscle cell phenotypic modulation in culture is associated with reorganisation of contractile and cytoskeletal proteins. Cell Motility and Cytoskeleton 2001; 49(3) 130-145. 
[51] Shanahan CM, Weissberg PL. Smooth muscle cell heterogeneity: patterns of gene expression in vascular smooth muscle cells in vitro and in vivo. Arteriosclerosis, Thrombosis and Vascular Biology 1998; 18(3) 333-338.

[52] Suzuki T, Nagai R, Yazaki Y. Mechanisms of transcriptional regulation of gene expression in smooth muscle cells. Circulation Research 1998; 82(12) 1238-1248.

[53] Hendrix JA, Wamhoff BR, McDonald OG, Sinha S, Yoshida T, Owens GK. 5' CArG degeneracy in smooth muscle \{alpha\}-actin is required for injury-induced gene suppression in vivo. Journal of Clinical Investigation 2005; 115(2) 418-427.

[54] Doran AC, Meller N, McNamara CA. Role of smooth muscle cells in the initiation and early progression of atherosclerosis. Arteriosclerosis Thrombosis and Vascular Biology 2008; 28(5) 812-819.

[55] Ordovas J, Shen, A. Genetics, the environment, and lipid abnormalities. Current Cardiology Reports 2002; 4(6) 508-513.

[56] Lichter P. New tools in molecular pathology. Journal of Molecular Diagnostics 2000; 2(4), 171-173.

[57] VanderLaan PA, Reardon CA. Thematic review series: the immune system and atherogenesis. The unusual suspects: an overview of the minor leukocyte populations in atherosclerosis. Journal of Lipid Research 2005; 46(5) 829-838.

[58] Scheckhuber C. Mitochondrial dynamics in cell life and death. Science of Aging Knowledge Environment 2005; DOI: 10.1126/sageke.2005.47.pe36.

[59] Yu E, Mercer J, Bennett M. Mitochondria in Vascular Disease. Circulation Research 2012; 95(2) 173-182.

[60] Anderson JL, Smith SC, Taylor Jr. RL. Spontaneous atherosclerosis in pigeons: A good model of human disease. In: Parthasarathy S. (ed.) Atherogenesis. Rijeka: InTech; 2011. p25-48. Available from http://www.intechopen.com/articles/show/title/ spontaneous-atherosclerosis-in-pigeons-a-good-model-of-human-disease (accessed 20 January 2012).

[61] Clarkson TB, Prichard RW, Netsky MG, Lofland HB. Atherosclerosis in pigeons: its spontaneous occurrence and resemblance to human atherosclerosis. American Medical Association Archives of Pathology 1959; 68(2) 143-147.

[62] Santerre R, Wight T, Smith S, Brannigan D. Spontaneous atherosclerosis in pigeons. A model system for studying metabolic parameters associated with atherogenesis. American Journal of Pathology 1972; 67(1) 1-22.

[63] Moghadasian MH, Frohlich JJ, McManus BM. Advances in experimental dyslipidemia and atherosclerosis. Laboratory Investigation 2001; 81(9) 1173-1183.

[64] St Clair R. The contribution of avian models to our understanding of atherosclerosis and their promise for the future. Lab Animal Science 1998; 48(6) 565-568. 
[65] St Clair R. Metabolic changes in the arterial wall associated with atherosclerosis in the pigeon. Federation Proceedings 1983; 42(8) 2480-2485.

[66] Smith SC, Smith EC, Taylor Jr. RL. Susceptibility to spontaneous atherosclerosis in pigeons: an autosomal recessive trait. Journal of Heredity 2001; 92(5), 439-442.

[67] Kanehisa M, Goto S, Hattori M, Aoki-Kinoshita KF, Itoh M. From genomics to chemical genomics: new developments in KEGG. Nucleic Acids Research 2006; 34(Database issue), D354-357.

[68] Nikitin A, Egorov S, Daraselia N, Mazo I. Pathway studio-the analysis and navigation of molecular networks. Bioinformatics 2003; 19(16) 2155-2157.

[69] Anderson JL. Differentially expressed genes in aortic cells from atherosclerosis-resistant and atherosclerosis-susceptible pigeons. PhD thesis. University of New Hampshire, Durham, 2008.

[70] Anderson JL, Taylor Jr, RL, Smith EC, Thomas WK, Smith SC. Differentially expressed genes in aortic smooth muscle cells from atherosclerosis-susceptible and atherosclerosis-resistant pigeons. Poultry Science 2012; 91(6) 1315-1325.

[71] Nikolsky Y, Ekins S, Nikolskaya T, Bugrim A. A novel method for generation of signature networks as biomarkers from complex high throughput data. Toxicology Letters 2005; 158(1) 20-29.

[72] GenBank. http://www.ncbi.nlm.nih.gov/genbank//(accessed 15 August 2012).

[73] Watanabe M, Sakomura Y, Kurabayashi M, Manabe I, Aikawa M, Kuro-O M, Suzuki T, Yazaki, Y, Nagal R. Structure and characterization of the 5 '-flanking region of the mouse smooth muscle myosin heavy chain (SM1/2) gene. Circulation Research 1996; 78(6) 978-989.

[74] Peltonen L, McKusick VA. Genomics and medicine: dissecting human disease in the postgenomic era. Science 2001; 291(5507) 1224-1229.

[75] Smith SC, Smith EC, Gilman ML, Anderson JL, Taylor Jr. RL. Differentially expressed soluble proteins in aortic cells from atherosclerosis-susceptible and resistant pigeons. Poultry Science 2008; 87(7) 1328-1334.

[76] Ortiz-Munoz G, Martin-Ventura JL, Hernandez-Vargas P, Mallavia B, Lopez-Parra V, Lopez-Franco O, Munoz-Garcia B, Fernandez-Vizarra P, Ortega L, Egido J, GomezGuerrero C. Suppressor of cytokine signaling modulate JAK/STAT-mediated cell responses during atherosclerosis. Arteriosclerosis, Thrombosis and Vascular Biology 2009 ; $29(4)$ 525-531.

[77] Saleh A, Srinivasula SM, Balkir L, Robbins PD, Alnemri ES. Negative regulation of the Apaf-1 apoptosome by Hsp70. Nature Cell Biology 2000; 2(8) 476-483.

[78] Semenza GL, Jiang B, Leung SW, Passantino R, Concordet J, Maire P, Giallongo A. Hypoxia response elements in the aldolase $\mathrm{A}$, enolase $\mathrm{A}$, and lactate dehydrogenase 
A gene promoters contain essential binding sites for hypoxia-inducible factor 1. Journal of Biological Chemistry 1996; 271(51) 32529-32537.

[79] Samani NJ, 33 co-authors. Genomewide association of coronary artery disease. The New England Journal of Medicine 2007; 357(5) 443-453.

[80] Zeller T, Blankenberg S, Diemert P. Genomewide association studies in cardiovascular disease-an update 2011. Clinical Chemistry 2011; 58(1) 92-103.

[81] Farouk S, Rader DJ, Reilly P, Mehta NN. CXCL12: a new player in coronary artery disease identified through human genetics. Trends in Cardiovascular Medicine 2010; 20(6) 204-209.

[82] Martin SK, Diamond P, Williams SA, To LB, Peet DJ, Fujii N, Gronthos S, Harris AL, Zannettino A.C.W. Hypoxia-inducible factor-2 is a novel regulator of aberrant CXCL12 expression in multiple myeloma plasma cells. Haematologica 2010; 95(5) 776-784.

[83] Popple A, Durrant LG, Spendlove I, Rolland P, Scott IV, Deen S, Ramage JM. The chemokine, CXCL12, is an independent predictor of poor survival in ovarian cancer. British Journal of Cancer 2012; 106(7) 1306-1313.

[84] Frank PG, Lee H, Park DS, Tandon NN, Scherer PE, Lisanti MP. Genetic ablation of caveolin-1 confers protection against atherosclerosis. Arteriosclerosis Thrombosis and Vascular Biology 2004; 24(1) 98-105. 